Accessibility and Informational Barriers to an Age Friendly Railway

\begin{tabular}{|r|l|}
\hline Journal: & Quality in Ageing and Older Adults \\
\hline Manuscript ID & QAOA-02-2021-0015.R2 \\
\hline Manuscript Type: & Research Paper \\
\hline Keywords: & $\begin{array}{l}\text { ageing, railway, public transport, railway station, mobility, accessibility, } \\
\text { information provision }\end{array}$ \\
\hline \multicolumn{2}{|l}{} \\
\hline
\end{tabular}




\section{Accessibility and Informational Barriers to an Age Friendly Railway}

\section{Introduction}

Being mobile and being able to travel in later life is linked to a good quality of life (see Holley-Moore \& Creighton, 2015 for review). Musselwhite and Haddad (2010, 2018) suggest mobility is important as it fulfils three levels of need, practical (the need to get from $A$ to $B$ to complete activities, as safely and reliably as possible), psychosocial (the need to fulfil roles and for independence and freedom associated with travel) and aesthetic (the need for mobility for its own sake). Many older people may have had to stop driving, or indeed, may have chosen not to drive, and public transport is a vital form of mobility to connect older people with their activities and meet their needs (Musselwhite, 2018). Musselwhite and Scott (2019) suggest people need mobility capital in order to complete the journeys people want to do in later life. They suggest infrastructure capital is the most important component of mobility capital, comprising of elements in the environment provided for individuals, for example, streets, stations, bus services, train services, buses and trains themselves. If these are poor then people need capital in different areas to fulfil their journeys, namely individual capital (resilience, skills, adeptness of using different modes or locations to overcome failures in infrastructure), social capital (friends, family or staff to help) and cultural capital (rules, laws and norms of society).

This study will look at how far infrastructure capital meets older people's needs on UK railways. Railways in the United Kingdom (UK) have seen a huge growth in the number of passengers. The number of passengers on the British rail network, for example, has increased 60\% between 1995 and 2017 (DfT, 2019). This increase in passenger travel on the railway has not been uniform. Despite there being an increase in travel among older people (aged over 70 ) in the past 10 years of around $11 \%$, there has been a fall in the number of older people (aged over 70) using rail of around 10\%. (DFT, 2019). This warrants further investigation; this paper examines what might be challenging for older people in using the rail network and how we might improve railway journeys, rolling stock and stations for older people. Previous research suggests accessibility, such as rolling stock and station design, along with information provision are key issues for older people on railway journeys (e.g. Musselwhite, 2018, Sundling et al., 2014). This paper builds on this previous research to add depth to these categories through undertaking co-research with older people themselves travelling the railways and reporting any problems on the trains and on the stations and platforms.

\section{Literature Review}

Previous research on older people and railways has been carried out examining existing passenger satisfaction data for those aged over 70 and using railways in the UK (Passenger Focus, 2015) by Musselwhite (2018) and through a survey of older rail users in Sweden aged 65-85 years of age. This has highlighted that elements relating to infrastructure capital - quality of journey, accessibility, station design and information provision are important for older people, coupled along with a social capital element, the presence of staff. Each of these is examined here in more detail. 


\section{Quality of journey}

An examination of data on older people's (people aged over70 years) rail travel in Britain using Passenger Focus (2015) survey data, who survey passenger transport satisfaction use for government and the industry was carried out by Musselwhite (2018). Overall, older people have higher satisfaction with their train travel than other ages. They are especially positive about overall journey experience compared to other age groups. They also show higher satisfaction with cost of the journey maybe because older people are able to take advantage of cheaper rail tickets, being more likely to travel throughout the day and not at expensive times of high demand like at peak times of use (Ormerod et al., 2015). Older people place great value in getting a seat on a train than other age groups. In fact, from 60 years onwards it becomes a higher priority than the cost of the ticket. In addition, cleanliness of the carriage and provision of toilet facilities is more important for those over the age of 70 than younger age groups. They value these over the length of the journey, perhaps showing value of travel time is synonymous with quality of the ride. They are less concerned, compared to younger and middle age rail passengers, about the availability of free wifi.

\section{Accessibility}

Accessibility is generally referred to as the relationship between the individual's functional capacity or capability and the demands of the physical environment (Iwarsson \& Stahl, 2003). A balance between the two is needed for something to be accessible. In Musselwhite an Scott (2019) model accessibility is a function of individual capital being traded with infrastructure capital, but can also involve cultural and social capital. Often the infrastructure around the older person stops them being able to use the train, as it does not match the person's capability and as such is inaccessible. Although there is high diversity of need among older people, around $30 \%$ of those aged over 70 have a mobility issue (DfT, 2019; Mackett, 2018). This is likely to impact on accessibility and in comfortable use of the railway, for example issues boarding and alighting moving in confined or crowded spaces. Sundling et al (2014) noted, moving inside the carriage was especially difficult when the train moved because of vibrations and jerkiness. This is exasperated when carrying luggage, and especially getting on and off the train with luggage and steps encountered (Sundling et al., 2014). Thus, accessibility onto the train, around the carriage and getting off again can be impeded for older people by design.

\section{Station design}

Station design must take into account the diversity of needs of older people. Stations are preferred that have indoor waiting areas and toilets, with accessibility being crucial, so lifts should be on all stations that require access by stairs (Musselwhite, 2018). Design of stations can help reduce vulnerability that older people may experience (Gilhooly et al., 2005). For example, older people feel more vulnerable and are less likely to use the station where there is a lack of visibility of other people, especially staff but also other passengers, a lack of lighting and where there are dark enclosed areas (Cozens et al., 2004). 


\section{Information provision}

Information provision for older people is important pre-journey and en-route (Ormerod et al., 2015). Information provision at stations was the most cited barrier to rail travel for older people in a study in Sweden (Sundling et al., 2014). This also contributed to poor orientation around the station, meaning signage is needed (Sundling et al., 2014). Information is needed both on train and at stations, especially for less frequent users and for when things do not go according to plan. In the Passenger Focus (2015) survey, older people value being kept informed about the journey and any delays higher than other age groups (Musselwhite 2018; Ormerod et al., 2015). Sundling et al (2014) notes the difficulty in hearing onboard train messages because of poor quality auditory systems or the acoustic system being out of order. Lamont, et al. (2013) investigated the extra planning that dyslexic travellers needed for planning a journey by rail and how the intervention of staff aware of their needs could help remove concern and anxiety over the journey. Similar may be found for older people, who may have poorer eyesight, have issues with cognitive overload, memory, concentration and learning, and could become overwhelmed by poorly designed signage (Ormerod et al., 2015).

\section{Presence of staff}

In line with Musselwhite and Scott's (2019) category of social capital, the importance of the presence of staff cannot be understated, both at railway stations and enroute and onboard, especially when the infrastructure is too difficult to navigate. This creates a feeling of security and safety but in terms of personal safety but also security about the journey itself (Musselwhite, 2018). Staff can also be useful in providing practical and physical help in carrying luggage or helping people on and off trains, something that is all too often missing but very much welcomed by older people (Sundling et al, 2014). Older people more than other groups value the importance of staff to help them at rail stations and on train services. They are more likely to trust information if it is given from authority figures, for example railway staff, and like the staff to be friendly and approachable (Musselwhite, 2018). Older people are more likely to use staff to get information on train delays or when things go wrong, whereas younger groups are more likely to use mobile ICT and apps (Gilhooly,et al.,2005; Musselwhite, 2011;). In addition, older people will use staff for backing up information they see on screens or hear over the announcements, which they trust less than younger groups (Musselwhite, 2018).

\section{Project Aim}

This project aimed to address what particular issues older people may have on a railway journey from station to station, using different rolling stock and stations. It builds on Musselwhite (2018) and Sundling et al (2014) by adopting older people as co-researchers to audit different rolling stock and stations and to examine barriers in depth and offer recommendations for improving the railway for older passengers Having older people as co-researchers was selected in order to bring out issues that are pertinent to individuals themselves, keeping it grounded in what is important to 
them. It is very useful where there is limited previous research in the field and more depth is needed to the findings.

\section{Methodology}

The methodology involved semi-structured audits of stations and rolling stock to further understand issues older people have with railways caried out by older people and accompanied by a researcher.

\section{Design}

In Great Britain there are 24 train operating companies who run train services and manage stations, along with network rail who own the track and most major stations. A sample of railway stations and rolling stock within the same company were examined for their age friendliness. A participative approach to the auditing took place, where older people themselves acted as co-researchers. The research team developed an audit sheet in line with previous research (Musselwhite, 2018 and Sundling et al, 2014) and then the participants themselves added additional own categories. Once on the journey they were encouraged to describe the barriers they experienced themselves but were encouraged to think about barriers that other older people might face (and clearly demarcate the two) An approach known as counterfactual method was employed to get people to think what if the situation was different and included two facets, (a) what if they themselves were less mobile and; (b) what if the train service or station was more crowded. Older people completed a proforma and then discussed this with the research team in interviews afterwards.

\section{Participants}

A total of 72.2 hours of auditing took place, split roughly $2 / 3$ on rolling stock (48.8 hours) and $1 / 3$ on the stations (23.4 hours) and 8 older people took part ( 5 female, 3 male; average age: 81 years), selected through a local research network database of people willing to take part in research. All participants were regular public transport users but not regular users of the railways, with 4 participants using on average once to twice a year and the other four having not used railways for 5 years or more. Participants would not have regular experience of using the stations or rolling stock studied. The station they boarded at the start of the audits they may be most familiar with, was not one of the stations examined. All of the participants described themselves as fit and healthy, though one male and two females suffered with both hip and knee problems. Timetables were devised to cover key rolling stock type used by that rail company, which included four different types of diesel multiple units and two different types of High-speed trains. Stations were placed into three bands; major stations with high capacity interchange, with high footfall on the network $(2 \mathrm{~m}+$ passenger entries and exits/year and over $1 \mathrm{~m}$ interchange), of which 3 were visited, medium footfall stations (between $1 \mathrm{~m}$ and $2 \mathrm{~m}$ passenger entries and exits and around 500,000 interchange) of which 4 were visited, and smaller less well used stations (under 1 million passenger entries and exits) of which 3 were visited. In addition, the timetables ensured that participants would experience morning and evening peaks at 
least one of the stations and onboard one type of train, meaning all stations had been covered at busier and quieter times.

Tools

Based on previous research (Musselwhite, 2018, Sundling et al., 2014), two basic audit proformas were drawn up, one for auditing the age friendliness of rolling stock and one for assessing age friendliness of stations. Each participant was given a proforma to follow and fill in themselves on paper, but in the spirit of co-production with older people as co-researchers, they were very much encouraged to add their own findings and not be bound by the categories given. The station proforma covered alighting and boarding, including gaps between train and platform, the state of the platform, including condition, tidiness, seating and lighting, information provision, amenities on the platform and on the concourse (cafes, toilet ticket office, ticket machines, waiting rooms etc.), station car parks, presence and helpfulness of staff, movement and access (on platforms, stairs, lifts, loading and unloading, crowding). The rolling stock audit covered boarding and alighting issues, seating (availability, comfort, cleanliness), general ambiance (lighting, air quality, noise etc.), crowding, staff presence and attitude, information provision (visual, announcements etc.) and amenities (trolley, buffet, toilets etc.)

\section{Analysis}

Data was analysed in two main ways, (1) from the data collected on audit sheets from the participants and (2) in the discussion with the participant co-researcher afterwards where the participant was asked to give their most important barriers. A standard text analysis technique was employed (after Patton, 2002) in order to identify similarities and differences, while collecting contextual information to help explain variation and diversity in more depth. Significant themes from the ones the co-researchers noted are reported, but so are themes that were highly valued by older people but only appear in certain contexts, for example certain types of rolling stock or certain contexts of station, so they may have only appeared from one person on one audit form.

\section{Findings}

Findings were placed into two key themes of accessibility and information. These were of equal importance to older people's journeys. Within each key theme sub-themes are reported in order ot significance to older people as noted in their audits.

\section{Accessibility}

\section{Boarding and alighting: Mind the gap.}

The most frequently reported issue for the participants themselves, also viewed as the most major, across all rolling stock and across all the stations audited with regards to the gap between the platform edge and the train (see figure 1). This was seen as significant for by participants for all older people in general and would be worse when carrying luggage. Participants preferred it where small steps were found to reduce the gap, but also where there were handles that were easily visible and could be used to 
help pull the person up onto the train or be used to help support weight while alighting. It is also helped with larger entrances and slide doors were preferred giving plenty of room to perform the manoeuvre,

"This is fine to get on, I can hoist myself up into the space, into the double doors and use the handle, the grab rail. It feels OK to be honest to do that despite the gap" (male, aged 78)

It was generally thought that the gap is actually worse in alighting situations, as there is nothing to support the weight of the individual as they lower themselves,

"I am anxious stepping down, I can't always see perfectly where to place my foot or what it'll feel like, like whether my body will take all my weight, as I step down. I mean it usually does! But it does make me anxious and more anxious than stepping up" (Male, aged 81)

Similarly, any bags or luggage is easier to hoist on than to bring down to the platform. The anxiety over performing these manoeuvres is worse when the situation is busy or crowded, as participants want to take their time over it and do not feel they can when under pressure from others, This would be made worse if the train was late or the staff use the whistle to "hurry" passengers along, which is felt could end in accidents,

"That was more trouble than last time as it was more crowded. It just adds to the discomfort. I feel I need to be quicker and I'm too worried to be quicker. I feel I'm holding people up though" (Female, aged 75)

The changes in lighting made it worse sometimes too, especially moving from a bright platform to a darker train,

"When I get on I can't see for a minute! It's so dark compared to the bright platform! Makes it dangerous. I need time to adjust" (Male, aged 81)

[Insert figure 1]

\section{Platforms.}

The station platforms themselves were found to be very clean and usually there was good natural lighting, but there were examples, even at very busy stations with high footfall, of very narrow platforms. Some participants noted that they and other older people they were thinking of would need more space to move around as they may be slower at walking and it can take them longer to change direction, and there was a feeling they were often in the way during busy times within narrow platforms. Again, this made some older people feel very anxious and could contribute to dangerous situations,

"It's not just the stress that people create when it's busy, but I feel I need room around me that I don't get. I need to space to move around me, to change direction and I especially need space when going up or down things, like stairs or onto the train" (female, aged 77). 
The participants wanted plenty of opportunities to sit down. Older style benches were commended on being practical and comfortable compared to more modern plastic or metal "bus stop" style seating,

"Oh this is nicer, proper wooden bench, not like those new metal things that are so uncomfortable and cold" (male, aged 76)

Canopies over the main seating areas were commended and the seating areas must be close to where the trains stop. The participants liked waiting rooms to be present at the stations. It was felt they needed better directions to these waiting rooms as they would be a good less crowded spot to wait where information is provided, ultimately reducing anxiety. They do not have to be of high quality, but must include ample seating, heaters or air conditioning, sheltered from outside, with announcements and next train information visually present, It was found that, across many different stations, the shorter trains do not stop near the waiting rooms, meaning the participants had to leave the waiting room early enough to get in position for the train or risk missing it altogether

"I want to be able to see and hear the announcements from where I am waiting. I don't want to have to get up every time to move to hear or see where the next train is going. Once I'm [sitting] down I need time to get up, so I don't want to move until I need to but I also need enough time to get to my train" (male, aged 81)

Toilets are a necessity for the participants and generally should be provided on each major platform, with large doors and brightly lit with contrasting colouring inside. Some smaller stations did not have such provision which was negatively received. One larger station only had toilets through the ticket barriers which again was felt to be negative.

Platform Lifts and stairs.

Generally, lifts were found clean and in good working order, with good information and of a large enough size to move around and bring luggage within. They were generally signposted well. The bridges over and under the platforms generally contained relevant information and were found to be clean and well lit. It was felt that the stairs were well lit but at two of the stations, each individual stair was of an odd height being rather too shallow. This helped the participants on the way up, but actually was difficult on the way down where the step down between stairs was not felt to be very natural,

"You'd think the shallower stairs would help with my knees and hips they way they are, but they don't they make it more awkward. It hurts to go down them. l'll take the lift next time" (female, aged 80)

A recorded message telling people to be careful on the stairs was played continuously or was motion triggered at most stations. The important reminder was felt to have some effect on being more careful, though it was generally thought that this would wear off if heard too regularly. Perhaps varying the recording with different ways of saying the message or using different voices may help, 
"It's funny hearing that message be careful be careful. I suppose it must help. Just annoys me is all! I think it doesn't make a difference to me. I am being careful! Maybe need to change it up a bit to keep me alert!" (male, aged 81)

\section{On-board: Room, light and level floors.}

On-board, the room needed to move around was acknowledged as generally being greater for the participants themselves and for older people they could think of, especially those with hip and knee problems, as people can turn to move so quickly and freely as younger people. There was a feeling this was not catered for in the design of small spaces. Coupled with this, it was also highlighted how important brightly lit and level floors are. Some of the newer intercity stock had raised floors above engines which created a small undulation for people to walk on which could affect gait and balance, especially where it was quite dark for people who had entered from a bright platform. In addition, the vestibule areas between carriages tended to be viewed as being quite dark.

"The fact the floor isn't level is off putting. I felt I might fall. I couldn't see it well after the bright platform. It's dark in these corridor bits" (female, aged 75)

The main cabin areas had good levels of natural light and were commended. The participants discussed quite liking the ability to open and close windows within the cabin to control the temperature better than climate-controlled air conditioned systems, but didn't like the smells of engine or noise associated with such windows. Grab rails throughout the coach is needed, on some rolling stock these were brightly coloured and at a good height to be used, on others they were too low and not of a contrasting colour, so were harder to use.

\section{On-board: Space for luggage.}

There were anxieties noted about limited space for luggage. It was felt that older people in general cannot always be expected to be able lift bags or cases above their head, and hence as much floor space for luggage is needed as possible,

"I can't lift a bag or case up there, so we need space at floor level. These floor spaces should be kept clear for us oldies to use" (male, aged 81)

There was a general feeling that as suitcases had become larger, the space in the carriages had not kept apace. The space for luggage should be near as possible to the entrance and exit areas and CCTV in these areas was welcomed for added security.

\section{On-board Toilets.}

Toilets were generally found to be well maintained. Apart from the wheelchair accessible toilets, they tend to be quite small as is the door into them, but they were felt to be largely inappropriate for older people, as one participant noted for herself,

"I'd always look for the disabled toilet if they weren't too far way. Just more room and space to move around I need these days" (female, aged 75) 
Sliding doors that were manually operated were often hard to use, causing embarrassment for one participant as they had to ask someone to help,

"I couldn't open the door to the loo. The sliding one. I wasn't strong enough. I had to ask a passer-by. That's very embarrassing and what if someone wasn't walking past" (female, aged 80)

The light in the toilet is generally good and bright. The water in the taps is easily operated but in all different rolling stock, the pressure of the water was too low. Hands free operation of water was preferred as was found on some rolling stock. It was felt the liquid soap dispenser could also be hands free. The only issue being the towel system, which requires pulling down a continuous towel and was hanging low on some types of rolling stock. It was also felt that this system is hard for older people who may not be strong enough to pull this down at such an odd angle. A hand dryer was a preferred solution, but again often when this was present, the pressure was not strong enough.

Information provision

On-board: Information and staff.

Staff were visible and friendly which was reassuring for all older people,

“The staff were great, they couldn't do enough. Nice chitter-chat and help with tickets and the timetable and the like. They were really helpful and nice" (male, aged 81)

There were some concerns over the public address system which older people could not hear well, as it was slightly muffled and not loud enough. The importance of this is significant, it was felt by the participants that older people are anxious about missing important messages,

Hope it wasn't important. Can't hear a word of that speaker on the train." (female, aged 75)

The text on safety information presented on the coach in written format was felt to be too small and was hard to read. Scrolling information was hard to read onboard, as it moved too fast for many of the older people to read it.

\section{Station signage.}

The most common and frequently reported issue across all station types, following boarding and alighting issues, was poor signage. This was worse the bigger and busier the station. One particular busy city centre station had several different types of signage all within a short distance around the stairs down between the platforms. These different types of signage included four warning signs above the stairs, six directional signs (in small font), a platform number sign, an entry and no-entry sign, and four information boards (figure 2). This caused significant overload for the participants at a place where they are involved in making a significant manoeuvre and the accident data shows that the place most accidents occur is at the stairs. The overload situation was especially an issue at busy times, 
"I needed to get across the platforms and those signs are confusing enough, look there's hundreds of them, direction, instructions, adverts and, let alone now it's getting busier the train came in. I don't think they've thought about it. Could be really dangerous couldn't it." (male, aged 81)

At a medium sized station, real-time next train information signs were found in the alcoves on the platform and were difficult to read, seemingly being too high up and overshadowed by the roof struts. At another larger, interchange station, it was observed that signage was completely obscured by roof struts on the platform, if a passenger walked more than about 5 meters from the sign, making it completely obscured from view further down the platform. The back of these signs are blank which leads to confusion, information could be provided on both sides.

At one medium sized station, information signs were found to be rather shadowed by larger advertising posters throughout the station, with the advertising posters being better placed to be read by customers than information signs. One information sign in particular was found on the stairs, which would be a hazard if someone stopped and read the sign.

At another medium sized station, there were good examples of signage which overcome some of the issues, with frequently repeated signage, so that there is a continuous message throughout the station (see figure 3). Signs at this station involved large font and were coupled with symbols throughout.

[insert figure 2]

[insert figure 3]

\section{Discussion}

There were two main issues older people discussed in terms of being important infrastructure barriers to their journeys on the railway, accessibility and information provision. In reading these findings it must be remembered that older people have a diverse set of needs and these may be different for different people. However, accessibility and information here were reported in equal strength and measure on the audit forms both for older people themselves on their journeys and when older people were thinking about others. Sub-themes teased out some of the key issues in more detail. The most common barrier for older people was boarding and alighting the train. This has been noted on previous research as being a place of great anxiety and concern for older people (Sundling et al., 2014), but we build on this, first by showing that it is present in a UK setting, as well as Sweden as in the Sundling et al (2104) research, and that more detail is given in this research about issues with stepping up onto the train or stepping down, the availability of grab handles or rails to support moving. Boarding and alighting both involve significant stress placed on leg muscles, knee and hip joints, as well as cardio-vascular demands that older people may have additional difficulty with (Afifi, Parke \& Al-Hussein, 2014; Riener, Rabuffetti \& Frigo, 2002). There was slightly more anxiety from older people completing the audits on 
alighting then boarding and this seems to be because there is some support for the weight from a grabrail to pull oneself up with while boarding, the equivalent of which is not available in alighting. Having to step down where there was a significant gap was an issue as there was nothing in front of them to help distribute the weight.

Lighting, surface texture and potential for a hand-rail have all been suggested as important in reducing falls ascending from stairs (Afifi et al., 2014), these need to be incorporated into carriage door design until level platforms are achievable. For example, steps can be unfolded as the carriage door opens and along with this, the findings here would suggest a hand rail should be part of this mechanism. The presence of a useful handle or grab rail to help hoist the person up again is also therefore crucial. In the rolling stock audits, it was large entrances with the presence of an easily noticeable grab rail that made boarding easier for older people. Moving around on the train, especially in narrow parts is an issue for older people, as noted in previous research (Sundling et al., 2014). Toilets being of a good usable standard is also needed as found in Sundling et al. (2014).

Lighting both on the platforms and on the train, (especially in vestibule areas) in areas of high movement and activity is a key barrier previous research has not found. It is particularly noticeable between coaches in areas people are moving around and especially where people have just entered or just about to alight from. It is known that poorly lit streets stop older people using them (Shumway-Cook, et al., 2003) and it seems the same can be seen here both on trains and on platforms with older people mentioning it as a major issue. Research suggests that someone aged 75 years can require 32 times the brightness they did at aged 25 (DfT, 2001) and the surfaces need to be flat. Having significant lighting can reduce potential for slips, trips or falls (Chang, 2016), who suggest lighting needs to be at significant levels at all times, warning against lighting that switches off when area is not used and on as someone approaches. Similarly examples were noted, where glare from sun meant signage on carriages or on platforms could not be read well and made parts of the area very dark and this is known to be an issue with older people; between 15 and 65 years, susceptibility to glare increases, and recovery form glare increases from two to nine seconds (DfT, 2001). Mackett (2014) notes usual street lighting can be between 3.5 to 10 lux but should be higher for station platforms and forecourt, at 50 lux, with lighting on stairs and underpasses up to 200 lux sand in places where people might need to see detail such as telephones, maps and displays, and the interactive areas of ticket machines.

With regards to platforms, signage could often cause overload on already busy locations. The audits revealed on the platforms themselves that signage was crucial to older people's sense of orientation and reducing them feeling lost, anxious and stressed, as has been found in previous research (Sundling et al., 2014). The audits here add to previous research that good, clear signage, that is repeated throughout, allowed the individual not to be overloaded and to focus on their gait, thus potentially reducing their likelihood of an accident is important. The signs must be visible from areas of the platform that are less busy, where older people may prefer to wait. It must be easy to see at a glance which signage is most important (Lamont et al., 2013). It is suggested a hierarchy of directional signs, followed by next train destination signs, 
information provision and, lastly, advertising boards. Too often it was found in the audit that advertising boards were largest and most prominent and placed in better more strategic positions than some more important signs. Auditory messages were often unheard, being difficult to ascertain what was being spoken, again noted in previous research (Sundling et al., 2014) and this could make older people anxious

The audits showed the importance of toilets and benches in platforms. Ideally, benches must have arm rests to help older people ease into and lift out of the seats. In the audits, stairs were generally found to be in very good condition, clean, with good lighting and with an abundance of visual and audible warnings. However, there was no uniform pattern to the visual warning however, with different warning signs placed at different locations within the vicinity of the stairs. By contrast the audible warnings were more uniform, making them easier to ignore. In addition, paint on the stairs between or on the edge of each varied between locations. More research is needed to ascertain whether varying the message keeps people alert, or indeed there is a best way of presenting the warning which reduces the number of trips.

Another issue highlighted by the audits was that the steps were often more shallow than was expected. Older people in the audit noted that while this was very beneficial when going up stairs, it was disconcerting when descending the stairs. The stairs need to be wide to accompany people of different backgrounds walking at different speeds up and down, perhaps segregated with an extra handrail in the middle would help. Older people are more likely to use a handrail, but then feel pressure from those wishing to overtake them from behind who may be faster. In addition, the lighting needs to be good in such areas it was generally found.

Lifts were often a preferred option for older people, but they can take a long time and be cited a long way from the main concourse, train alighting and disembarking zones which mean they are less likely to be used. In addition to standardising paintwork, it is again suggested that signage is crucial in these locations.

Staff were important to older peoples journey as has been found in previous research on railways and on buses too (Musselwhite, 2018; Sundling et al., 2014). They can placate some of the anxiety found by older people, highlighting how social capital can be traded where infrastructure capital is lacking in Musselwhite and Scott (2019) model of mobility capital.

This clearly highlights a major barrier for older people's mobility is the surrounding infrastructure, and that this is not matching the needs and capabilities of an ageing population. To help older people stay mobile, and to reduce negative effects of reduced mobility (Holley-Moore \& Creighton, 2015), there is a need to improve such infrastructure, especially around accessibility and information provision. Although this has been examined here in a railway context, it mirrors similar findings for mobility in general from Musselwhite and Scott (2019) who note the most important aspect keeping older people mobile in later life is infrastructure capital, with social capital providing some trade off when infrastructure is poor. The major barriers are those of infrastructure and staff members can help overcome some, but not all, of these, for example help with information, lifting luggage on and off and getting on and off the train. Musselwhite and Scott (2019) also note how far cultural capital can provide 
resource for infrastructure capital, for example as older people are likely to be users of public buses, bus design has begun to reflect the needs of these users. Indeed, in many countries, level access has become a legal requirement on public buses, but this has not always been replicated on railways. Musselwhite and Scott (2019) note that individual capital, including the functional ability, skills and capability of the individual can help when infrastructure is poor. Crucially this includes experience of using the mode of transport and given use of railways is not very high by older people, they are not experienced users. Clearly there are gaps in infrastructure not being able to be met by social, cultural or individual capitals in railway usage meaning older people are less likely to use them. There needs to be more involvement of older people in the design of railway carriages and stations to build in the design requirements of an ageing population, and more acknowledgement that older people could be a attractive railway customer that needs being provided for.

It must be remembered that these are not the only infrastructure barriers to using the railway for older people. Services may not serve the destinations older people want to go to. Parkhurst et al (2014) and Musselwhite (2021) note that transport planning including planning routes and timetables for railways tends to favour business and commuting type journeys, favouring fast inter-city journeys at the expense of local, slower services stopping at more stations, the latter suiting the more varied journeys older people may be making. There are also push/pull barriers of other modes of transport that may provide extra comfort, safety, as well as more direct routes and the car remains very hard to compete with in terms of comfort, journey time, perceived cost and directness of journeys. However, some of the barriers discussed in this research do help illuminate what might be done to potentially make railways a more attractive offering.

More research is evidently needed, perhaps some ethnographic research following passengers on journeys using stations on the network at different times of the day. This study has not included fares and pre-trip planning element of the journey and not tested accessibility or staff attitude. These are all areas known to be important in public transport journeys for older people (Musselwhite, 2018). Hence, research to complement these findings are needed examining planning and buying tickets and support from staff, perhaps through some travel ethnography.

It is acknowledged that only 8 participants took part. This is justified as providing robust enough data in two main ways. First this study is explorative, there is no other study addressing these issues in detail and hence it would be hard to involve a larger more quantitative approach until we know what to look for. Secondly, the amount of hours covered by the participants and the breadth of rolling stock and station types covered gives depth to the answers, although generalisation would need further research. The findings from this research therefore lend themselves to be tested in a more quantitative manner with a larger number of participants. The participants did not, on the whole, have vast recent experience or knowledge of using the railways, so further studies should include a wider selection of participants carrying out audits with people from a variety of backgrounds, including those with greater experience of using railways. Familiarity with the railway may overcome some of the issues experienced or may reveal different more persistent issues, for example. 
Overall, the methodology of involving older people as co-researchers completing their own audits has worked well for examining in detail some of the issues about using the railway. It seems issues pertinent to some older people may be overlooked by railway companies. Musselwhite (2021) notes the importance of involving older people in transport planning and public transport service provision and this methodology might be a way of doing this. Some of the findings have implications for other public transport modes as well, for example in bus use, providing good quality lighting, step-free access and good information provision, and in provision of good infrastructure for walking, keeping areas wide, and providing access to benches, sheltered where possible and toilets. Without attending to the needs of older people, it could reduce their ability to go out and connect to the people, places and things they want to, creating isolation and potentially contributing to loneliness. However, as Musselwhite and Haddad $(2010,2018)$ note psychosocial and aesthetic needs must also be taken into account above and beyond these utilitarian needs. These areas of needs would be interesting to study in future research.

\section{Conclusion}

The findings in this paper suggest that getting the infrastructure right, especially in terms of accessibility and information provision, is vital for older people's mobility. Older people may be being put off from using the railway through a number of issues. Concerns over boarding and alighting are key to this, especially where there is a large gap between the platform and the carriage and a lack of grab rails to support this, which is compounded when carrying luggage. In addition, poor signage make the railways a confusing place for anyone with any eyesight, hearing or cognitive challenges. Lighting is not especially good in the vestibule areas of the carriages and in some areas on the station. The thoroughfare of the car park, the station frontage and concourse are often busy, confusing and poorly lit areas. Stairs are generally well looked after but they can be overloaded with signs and had unusually shallow or irregular steps contained within which can cause anxiety.

To make the railway more age friendly, improvements need to be made on stations in terms of better signage, lighting, stairs, the movement spaces from car park and concourse through to station platforms. On trains similarly, lighting and signage is important, but boarding and alighting needs to be improved with wide entrances, grab rails and the railway must work towards level, step-free access from station to carriage.

It is suggested that signage is needed to be changed. Large clear, repeated signage, with directional signs having greatest prominence, followed by next train signs, information signs, with advertisements being least prominent. These need to be visible from all parts of the platform. The platforms need to be as wide as possible, contain benches and have as much natural lighting as possible. There needs to be a re-visiting of the warnings accompanying stairs and research into it's effectiveness. The shallow nature of the step is disconcerting and needs revisiting. Stairs should be cluster free and extra handrails placed in the middle of wider stairs to help numbers going up and down. Having a one-way system on the stairs is suggested as good practice. Areas leading from interchange (car park, bus stops, taxi ranks) and station frontage, through 
ticket offices to the platform again need to be well lit, contain appropriate, repeated signage, but also be considered as areas for potential sitting and dwelling and not just places for movement. Further research is needed on evidencing best practice, to see if it the suggested changes make a difference to accident rates. Another major change needed is to work towards having step free access onto the carriages from the platform. Until then, supporting people alighting from the service with grab rails needs to be considered. Overall, to ensure older people's mobility needs are met, more involvement of them in the design of railways' carriages and stations are needed.

\section{References}

Addis, M., \& Mahalik, J. (2003). Men, masculinity, and the contexts of help seeking. American Psychologist, 58, 5-14.

Afifi, M., Parke, B., \& Al-Hussein, M. (2014). Integrated approach for older adult friendly home staircase architectural design. Automation in Construction, 39, 117-125.

Chang, W. R., Leclercq, S., Lockhart, T. E., \& Haslam, R. (2016). State of science: occupational slips, trips and falls on the same level. Ergonomics, 59(7), 861-883.

Courtenay, W. H. (2000). Constructions of masculinity and their influence on men's wellbeing: a theory of gender and health. Social Science \& Medicine, 50, 1385-1401.

Cozens, P., R. Neale, D. Hillier, \& Whittaker, J. (2004). Tackling crime and fear of crime while

waiting at Britain's railway stations. Journal of Public Transportation 7 (3): 23-41.

Department for Transport. (2001). Older drivers: a literature review. London: Department for Transport.

Department for Transport. (2019). National Travel Survey. Retrieved from http://www.dft.gov.uk/statistics/series/national-travel-survey/

Gilhooly, M., Hamilton, K., O'Neill, M., Gow, J., Webster, N., Pike, F., \& Bainbridge, C. (2005). Transport and Ageing: Extending Quality of Life for Older People via Public and Private Transport. ESRC Report.

Health and Safety Executive. (2015). Reporting accidents and incidents at work A brief guide to the Reporting of Injuries, Diseases and Dangerous Occurrences Regulations 2013 (RIDDOR). Retrieved from http://www.hse.gov.uk/pubns/indg453.pdf

Holley-Moore, G. \& Creighton, H. (2015). The Future of Transport in an Ageing Society. Age UK, London.

Iwarsson, S. \& Ståhl, A. (2003) Accessibility, usability and universal design positioning and definition of concepts describing person-environment relationships. Disability and Rehabilitation 25(2), 57-66

Lamont, D., Kenyon, S., \& Lyons, G. (2013). Dyslexia and mobility-related social exclusion: the role of travel information provision. Journal of Transport Geography, 26, 147-157. 
Mackett, R. (2014). Overcoming the barriers to access for older people. Age Action Alliance document. Available at: http://ageactionalliance.org/wordpress/wpcontent/uploads/2014/11/Overcoming-the-barriers-to-access-Nov-14.pdf $\quad$ (last accessed 2nd February 2021)

Mackett, R. (2018). Older People's Travel and its Relationship to their Health and Wellbeing. In C.B.A. Musselwhite (ed.). Transport, Travel and Later Life (Transport and Sustainability), 10, 15-36.

Moore, J. X., Lambert, B., Jenkins, G. P., \& McGwin, G. (2015). Epidemiology of highheel shoe injuries in US women: 2002 to 2012. J. Foot Ankle Surg, 54, 615-619.

Musselwhite, C. B. A. (2018). Public and Community Transport In C.B.A. Musselwhite (ed.). Transport, Travel and Later Life (Transport and Sustainability), 10, 117-128.

Musselwhite, C. (2021) Mobility planning/policies for older people. In: Vickerman, Roger (Ed.) International Encyclopedia of Transportation. vol. 6, pp. 59-63. Oxford, UK: Elsevier Ltd.

Musselwhite, C. and Haddad, H. (2010). Mobility, accessibility and quality of later life. Quality in Ageing and Older Adults. 11(1), 25-37.Musselwhite, C.B.A. and Haddad, H. (2018). Older people's travel and mobility needs. A reflection of a hierarchical model 10 years on. Quality in Ageing and Older Adults, 19(2), 87-105

Musselwhite, C. and Scott, T. (2019). Developing a Model of Mobility Capital for an Ageing Population. International Journal of. Environmental Research and Public Health 16, no. 18: 3327

Ormerod, M. Newton, R., Philips, J., Musselwhite, C., McGee, S \& Russell, R. (2015). How can transport provision and associated built environment infrastructure be enhanced and developed to support the mobility needs of individuals as they age? Future of an ageing population: evidence review Foresight, Government Office for Science, London, UK

Passenger Focus (2015). National Rail Passenger Survey.

Patton, M. Q. (2002). Qualitative research and evaluation methods. Thousand Oaks, CA: Sage.

Parkhurst, G., Galvin, K., Musselwhite, C., Phillips, J., Shergold, I. \& Todres L. (2014). Beyond Transport: Understanding the Role of Mobilities in Connecting Rural Elders in Civic Society in Hennesey, C., Means, R., Burholt, V., (Eds). Countryside Connections: Older people, Community and Place in Rural Britain. Policy Press, Bristol 125-175.

Riener, R., Rabuffetti, M., \& Frigo, C. (2002). Stair ascent and descent at different inclinations. Gait Posture, 15, 32-44.

Shumway-Cook A, Patla A, Stewart A, Ferrucci L, Ciol MA \& Guralnik J. 2003. Environmental components of mobility disability in community-living older persons. Journal of the American Geriatrics Society 51(3):393-398. 
Sundling, C., Berglund, B., Nilsson, M. E., Emardson, R., \& Pendrill, L. R. (2014). Overall accessibility to traveling by rail for the elderly with and without functional limitations: the whole-trip perspective. International journal of environmental research and public health, 11(12), 12938-12968. 


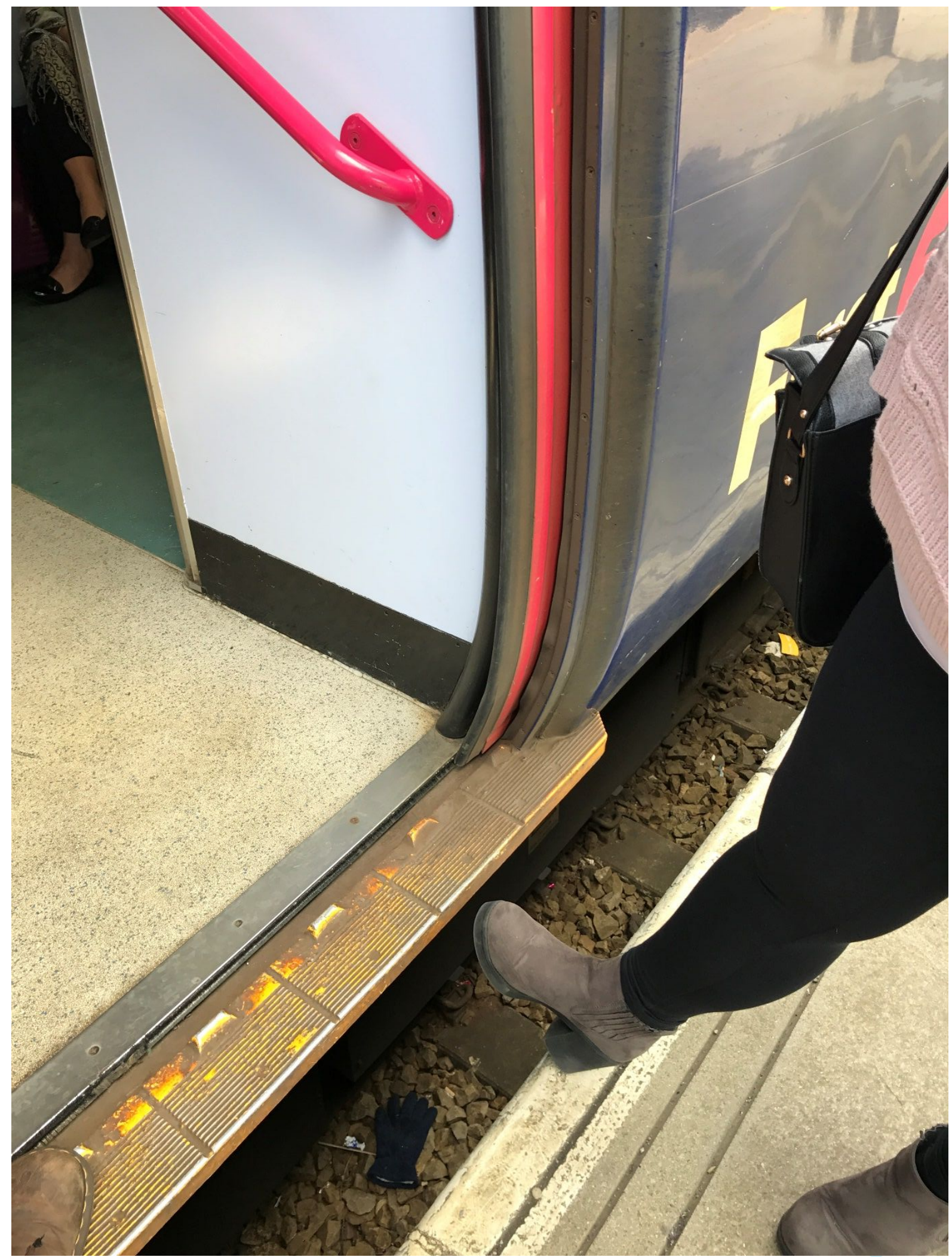

Figure 1: Step across and up onto the carriage is dangerous for older people as noted by the participants in the study. 


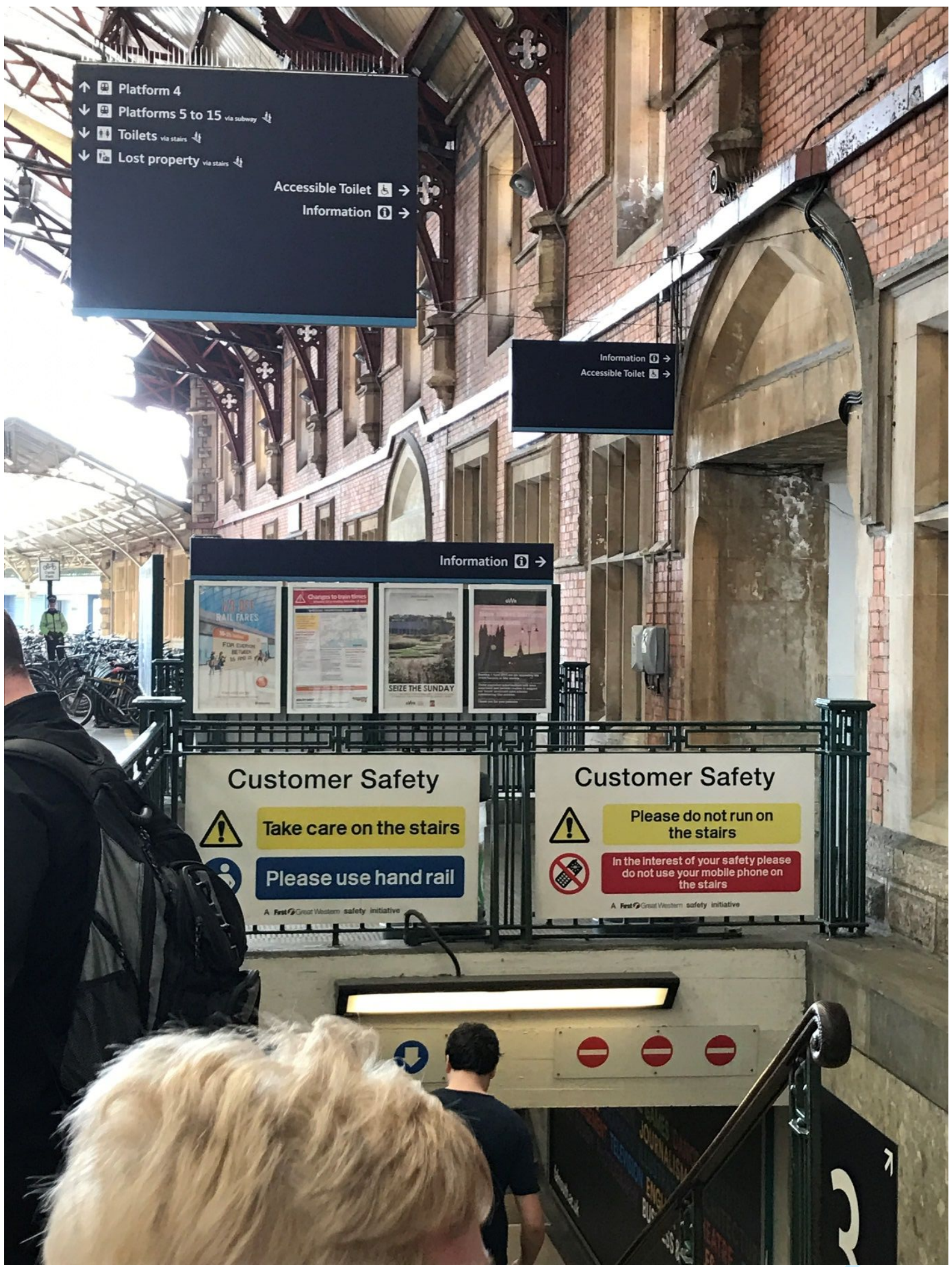

Figure 2: Too many signs of different types, information, warning, directional, all placed by the stairs to different platforms, a zone of maximum conflict, was as a place of potential overload by the participants. 


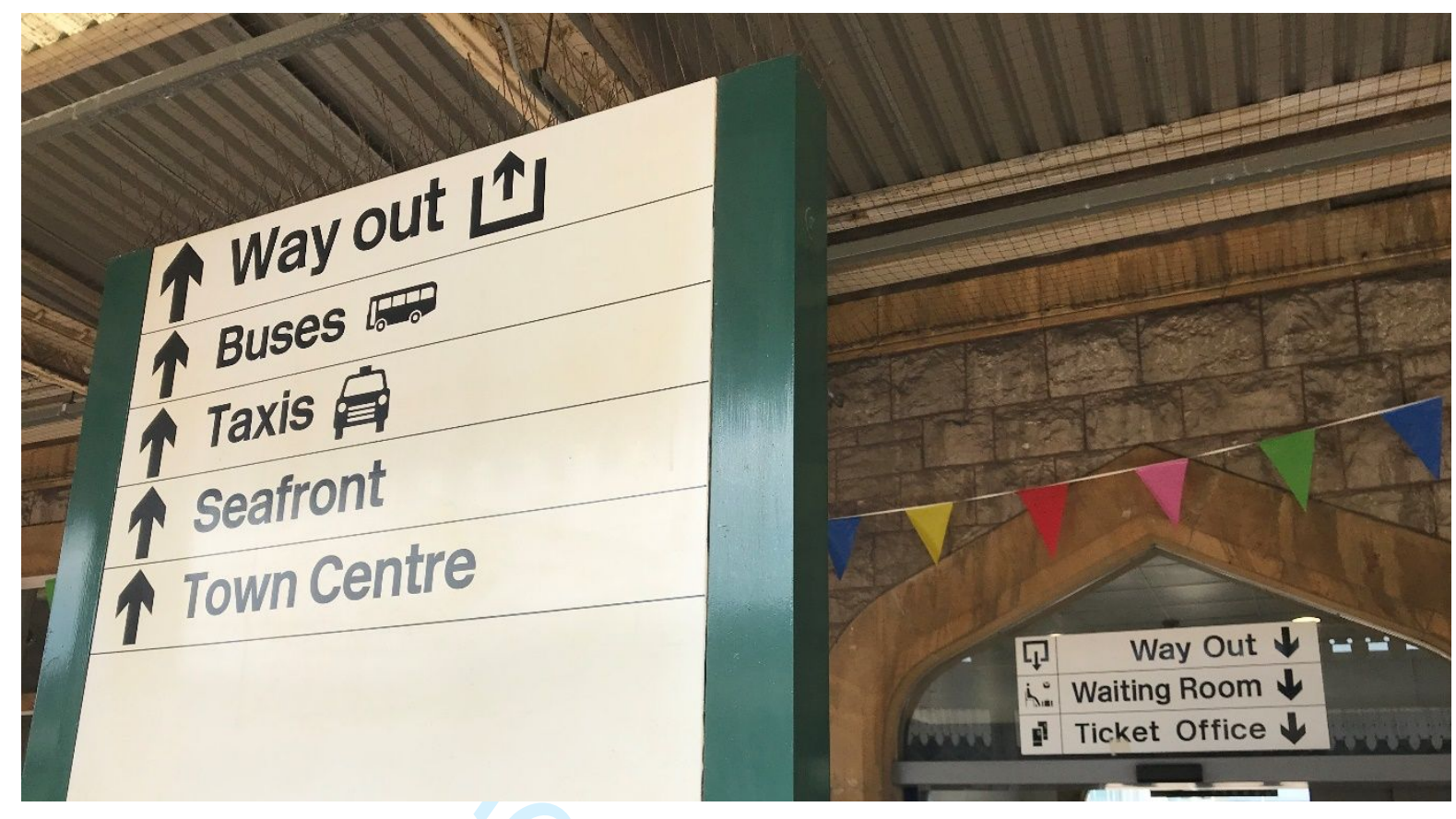

Figure 3: Well-designed signage was viewed positively by the participants when it was in large font and repeated throughout the station. 